\title{
Review of the Nomenclature of the Retaining Ligaments of the Cheek: Frequently Confused Terminology
}

\author{
Yeui Seok Seo ${ }^{1}$, Jennifer Kim Song ${ }^{2}$, Tae Suk Oh${ }^{3}$, Seong Ihl Kwon ${ }^{4}$, Tanvaa Tansatit ${ }^{5}$, \\ Joo Heon Lee ${ }^{1}$
}

${ }^{1}$ Area88 Plastic Surgery Clinic, Seoul; ${ }^{2}$ VIVA Plastic Surgery Clinic, Busan; ${ }^{3}$ Department of Plastic Surgery, Asan Medical Center, University of Ulsan College of Medicine, Seoul; ${ }^{4}$ IDEA Aesthetic Plastic Surgery Clinic, Seoul, Korea; ${ }^{5}$ The Chula Soft Cadaver Surgical Training Center and Department of Anatomy, Faculty of Medicine, Chulalongkorn University and King Chulalongkorn Memorial Hospital, Bangkok, Thailand

Since the time of its inception within facial anatomy, wide variability in the terminology as well as the location and extent of retaining ligaments has resulted in confusion over nomenclature. Confusion over nomenclature also arises with regard to the subcutaneous ligamentous attachments, and in the anatomic location and extent described, particularly for zygomatic and masseteric ligaments. Certain historical terms-McGregor's patch, the platysma auricular ligament, parotid cutaneous ligament, platysma auricular fascia, temporoparotid fasica (Lore's fascia), anterior platysma-cutaneous ligament, and platysma cutaneous ligament-delineate retaining ligaments of related anatomic structures that have been conceptualized in various ways. Confusion around the masseteric cutaneous ligaments arises from inconsistencies in their reported locations in the literature because the size and location of the parotid gland varies so much, and this affects the relationship between the parotid gland and the fascia of the masseter muscle. For the zygomatic ligaments, there is disagreement over how far they extend, with descriptions varying over whether they extend medially beyond the zygomaticus minor muscle. Even the 'main' zygomatic ligament's denotation may vary depending on which subcutaneous plane is used as a reference for naming it. Recent popularity in procedures using threads or injectables has required not only an accurate understanding of the nomenclature of retaining ligaments, but also of their location and extent. The authors have here summarized each retaining ligament with a survey of the different nomenclature that has been introduced by different authors within the most commonly cited published papers.

Keywords Cheek / Fascia / Ligaments / Rejuvenation / Anatomy
Correspondence: Joo Heon Lee Area88 Plastic Surgery Clinic, Yuri build 5 th floor, 822 Seonreuong-ro, Gangnam-gu, Seoul 06014, Korea Tel: $+82-2-548-0088$ Fax: +82-2-554-7557 E-mail: jj2197@naver.com

This review article was presented at the Aesthetic Plastic Surgery 2015 Symposium of the Korean Society of Aesthetic Plastic Surgery on March 28, 2015, in Seoul, Korea and at the Aesthetic Plastic Surgery 2016 Symposium of the Korean Society of Aesthetic Plastic Surgery on March 12, 2016, in Seoul, Korea.

No potential conflict of interest relevant to this article was reported.

Received: 1 Jun $2017 \bullet$ Revised: 29 Jun $2017 \bullet$ Accepted: 30 Jun 2017

pISSN: 2234-6163・ elSSN: 2234-6171 • https://doi.org/10.5999/aps.2017.44.4.266• Arch Plast Surg 2017;44:266-275

\section{INTRODUCTION}

The term 'retaining ligament' was coined by Dr. Mar McGregor for 'the area of fibrous attachment' [1], which Kaye [2] later officially named 'McGregor's patch.' In 1989, Furnas [3,4] reported that it is conceptually accepted as a connective tissue attach- 
ment between the facial skin and the skeleton - in effect, a homologous anatomical structure to the retaining ligaments in the digits.

Since Furnas reported the concept of the retaining ligament and fascia in 1989, up to this day, numerous reports [3-15] have been offering supporting evidence of the anatomic description of fibrous connective tissue in the face, whether extending the scope of the investigation with more detail, more histological evidence, or more clinical evidence, all anatomic descriptions have been similar. Although sharing similar fundamental features with unanimous use of the term 'zygomatic and masseteric ligament,' variability in the details on the extent of the subcutaneous ligamentous attachments has intensified the confusion in proper selection of terms for each retaining ligament.

\section{FREQUENTLY CONFUSED TERMINOLOGY REGARDING THE CHIEEILIGAMENTS}

\section{Subcutaneous ligamentous attachments}

Many articles published after Furnas challenged his concept, offering alternative nomenclature of their own for the retaining ligaments, which has provoked confusion in the use and categorization of the retaining ligaments in the face ever since. The terminology used for the retaining ligaments of the cheek vary in the literature due to the use of terms named for different interpretations of the anatomy, or by its location (Table 1 ) $[1-5,12$,
16-27].

The most confusing perspective arises from the subcutaneous ligamentous attachments. Furnas [3] and Stuzin $[5,8]$ rejected the term 'cutaneous' to describe the retaining ligaments with subcutaneous ligamentous attachments with a skeletal origin. On the other hand, Özdemir et al. [12] adopted the term "cutaneous" generally for ligamentous cutaneous attachments, regardless of their origin. However, Özdemir did not use 'cutaneous' for the mandibular ligament, which seems inconsistent. Mendelson (2000) created his own terminology categorizing the retaining ligaments of the face as adhesion, septum, and true ligaments, and did not utilize the term 'cutaneous' at all [10,20,28].

Somewhat different names for identical retaining ligaments have arisen because of the intended purpose for categorizing the ligamentous attachment, as in the case of Mendelson, or due to the individual variability of the appearance of the ligamentous attachments found in the clinical setting or in cadaver specimens.

\section{McGregor's patch $[1,2]$}

'McGregor's patch' had been used synonymously with the zygomatic cutaneous ligament or the zygomatic ligament $[3,5,7$, $11,29]$.

The original description of the 'McGregor's patch' presented in 1959 referred to "an area of fibrous attachment between the anterior edge of the parotid fascia and the dermis of the skin of the cheek" [1] (Fig. 1A, B). The definition was meant to em-

\section{Table 1. Confused nomenclatures of the retaining ligaments of the cheek}

\begin{tabular}{|c|c|}
\hline Cheek ligaments & Presumed synonym \\
\hline \multicolumn{2}{|l|}{ Malar area } \\
\hline McGregor's patch (1959) $[1,2]$ & $\begin{array}{l}=\text { Zygomatic ligament (Furnas } 1989 \text { [3]) } \\
=\text { Zygomatic cutaneous ligament (Özdemir } 2002[12])\end{array}$ \\
\hline \multicolumn{2}{|l|}{ Peri-auricular area } \\
\hline Platysma auricular ligament (Furnas 1989 [3]) & =Auricle-platysma ligament (Botti 2012 [16]) \\
\hline Parotid cutaneous ligament (Stuzin 1992 [5]) & $\begin{array}{l}=\text { Platysma auricular fascia (Furnas } 1994[4,17,18]) \\
\fallingdotseq \text { Preauricular parotid cutaneous ligament (Özdemir } 2002 \text { [12]) }\end{array}$ \\
\hline Platysma auricular fascia (PAF, Mendelson $2008[19,20])$ & $\begin{array}{l}\text { > Platysma auricular ligament (Furnas } 1989 \text { [3]) } \\
\text { > Parotid cutaneous ligament (Stuzin } 1992[5]) \\
\text { > Platysma auricular fascia (Furnas } 1994[4,17,18] \text { ) } \\
\text { > Auricle-platysma ligament (Botti } 2012 \text { [16]) } \\
\text { > Preauricular parotid cutaneous ligaments (Özdemir } 2002 \text { [12]) } \\
\text { > Lore's fascia (Labbé } 2006 \text { [21-23]) }\end{array}$ \\
\hline Temporoparotid fascia (Lore 1973 [24,25]) & $\begin{array}{l}=\text { Lore's fascia (Labbé } 2006 \text { [21-23]) } \\
=\text { Tympanoparotid fascia (Labbé 2006 [21,26]) }\end{array}$ \\
\hline \multicolumn{2}{|l|}{ Peri-masseteric area } \\
\hline Anterior Platysma-cutaneous ligament (Furnas 1989 [3]) & $\begin{array}{l}\fallingdotseq \text { Masseteric cutaneous ligament (Stuzin } 1992[5]) \\
\fallingdotseq \text { Parotidomasseteric cutaneous ligament (Özdemir } 2002 \text { [12]) }\end{array}$ \\
\hline Platysma cutaneous ligament (Özdemir 2002 [12]) & $\fallingdotseq$ Mandibular septum (Pessa 2008 [27]) \\
\hline
\end{tabular}

Retaining ligaments of the cheek are presented in variable ways in the literature due to terminology based on different interpretations of the anatomy, or by their location. $=$, identical nomenclature or in the same location addressed by the original namer; $\fallingdotseq$, difference in nomenclature at a similar location to that addressed by the original namer; > , including the region described by the original namer. 
phasize the warning that this patch is a necessity and that in making cuts to obtain good skin drapage, there is a risk of injuring the parotid fascia. The idea was to raise awareness of the existence of the facial nerve branches and parotid duct running underneath [3].

Alghoul and Codner [30] also emphasized that finding this patch, which is believed to be the perforator of the transverse facial artery, during exploration alerts the surgeon to the presence of blood vessels ahead (Fig. 1B). Upon finding McGregor's cutaneous ligaments, they mentioned 3 nearby structures of importance: the transverse facial artery, parotid duct, and zygomatic branch of the facial nerve that penetrates the parotid-masseteric fascia in that region. However, the specific extent of McGregor's patch itself is not described definitively; it is unclear whether it solely refers to the zygomatic cutaneous ligaments or, in addition, includes the masseteric ligaments. In that sense, we agree with the idea of Alghoul and Codner [30]. The extent of this region of McGregor's patch extends from the point of appearance of the perforating branch of the transverse facial artery to the area covering the zygomatic cutaneous ligament and the upper masseteric cutaneous ligament (Fig. 1C). Measurements of its dimensions are approximately $3 \mathrm{~cm}$ anterior to posterior, and approximately $3.5 \mathrm{~cm}$ cephalic to caudal. Thereby, considering the level of dissection and description, there is common agreement that it is tethering the malar fat pad (malar superficial musculoaponeurotic system, SMAS) $[3,29,30]$. Release of the McGregor's patch will result in freed mobility of the midfacial skin, in which is an important technique in adopting malar SMAS dissection to performing a subSMAS facelift surgery.

\section{Platysma auricular ligament (Furnas [3]) and auricle- platysma ligament (Botti [16])}

Furnas [3] reported that "The posterior border of the platysma recedes into an intricate fascial condensation that often attaches intimately to the overlying skin. This structure provides firm anchorage between the platysma and the dermis of the inferior auricular region".

O'Brien et al. [31] has described the platysma-auricular ligament (PAL) as extending from the auricle in an inferior direction along the posterior border of the platysma. A thorough de-

\section{Fig. 1. McGregor's patch}

(A) Schematic illustration of McGregor's patch. This patch is composed of a perforator of the transverse facial artery running towards the malar area, zygomatic ligaments, and upper masseteric ligaments. (B) A fresh frozen cadaveric dissection shows the condensed fibrotic tissue between the superficial musculoaponeurotic system (SMAS) and the skin in the zygoma. Red circle, McGregor's patch; Heart, skin flap; Clover, SMAS. (C) McGregor's patch contains zygomatic and masseteric ligaments. The perforating vessels are present. Yellow diamond, Zygomatic cutaneous ligament; Blue diamonds, Masseteric ligaments; Green arrow heads, perforators of the facial artery; Heart, skin flap; Clover, SMAS.
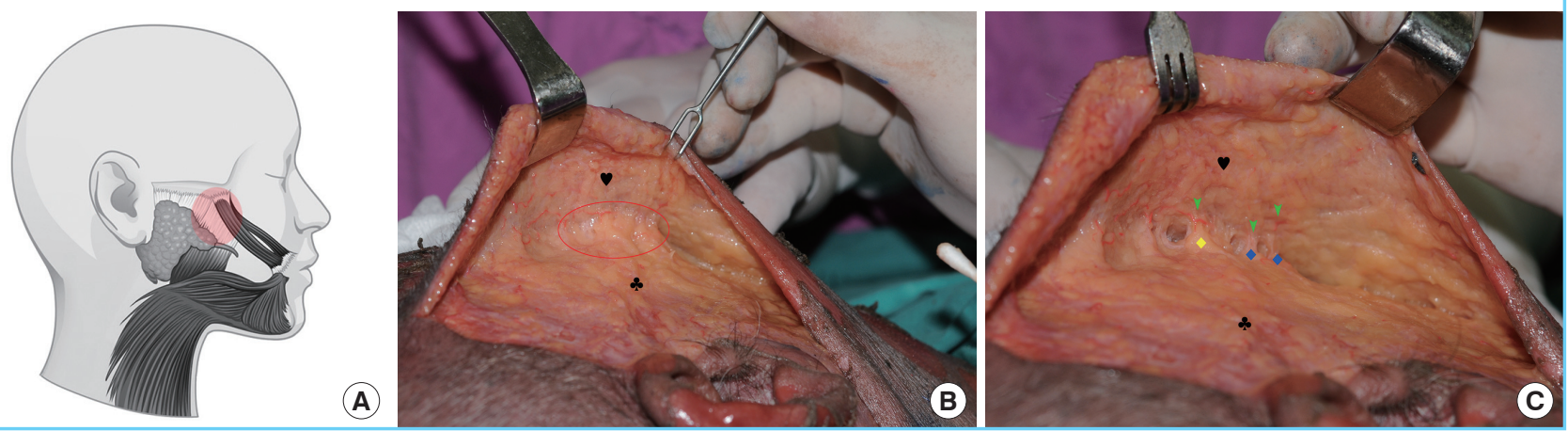

Fig. 2. Platysma auricular ligament and auricle-platysma ligament

(A) Schematic illustration of the platysma auricular ligament and auricle-platysma ligament. (B) In fresh frozen cadaveric dissection, the trapezoidal fibrous tissue exists between the ear lobe and the posterior border of the platysma muscle. Diamond: platysma auricular ligament (auricle-platysma ligament). Heart, parotid masseteric fascia (deep fascia); Clovers, The superficial musculoaponeurotic system is reflected.
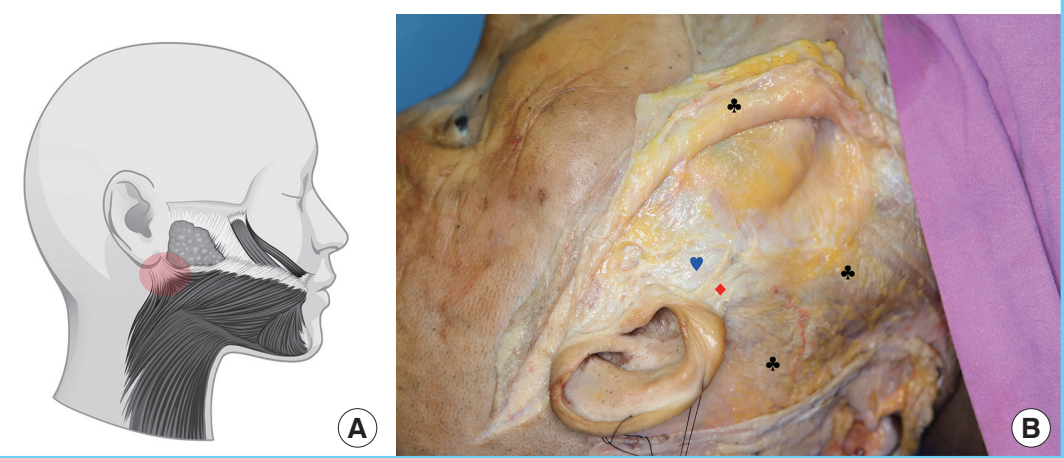
scription by Botti [16] also presents a structure originating from the dermis of the earlobe and the superficial parotid fascia that fans out to insert into the superolateral border of the platysma. Although Botti [16] named the structure with more emphasis on its origin and named it the auricle-platysma ligament, it is identical to the structure initially indicated as the 'platysma auricular ligament' by Furnas [3] in his illustration (Fig. 2).

Fresh frozen cadaver dissection performed by the authors has confirmed a trapezoidal shape of a deep fibrotic expansion located at the superficial layer, extending from the dermis of the inferior auricular region to the lateral border of the platysma. We observed that as it completes its course with the insertion to the lateral border of the platysma, the distribution and the morphology of the platysma auricular ligament (auricle-platysma ligament) differs according to the shape of the platysma.

During the fresh frozen cadaver dissection, we also learned that the tension applied to the platysma auricular ligament transmits such that it shifts the ear axis in the anteroinferior direction.

However, several observations reveal that the platysma auricular ligament is obviously a different structure from the parotic masseteric fascia (deep fascia).

\section{The parotid cutaneous ligament (Stuzin et al. [5]),} platysma auricular fascia (Furnas $[4,17,18]$ ) and preauricular parotid cutaneous ligament (Özdemir [12])

Nevertheless, back in 1989, aside from the illustration, Furnas [3] did not make mention of the direct relevance of the platysma auricular ligament to the parotid fascia. Then, later in 1994, he discovered that the fascial condensation actually originates from the parotid fascia and he renamed it the platysma auricular fascia $[4,17,18]$. Furnas's transition from considering the part to be a ligamentous structure to thinking of it as a fascial condensation, and moreover, equating the term with Stuzin's 'parotid cutaneous ligament' (1992) [5] and Özdemir's [12] 'preauricular parotid cutaneous ligament' (2002), can be interpreted as indicating that Furnas had conceptualized a broader range of fibrous connective tissue in the preauricular area in describing the platysma auricular fascia (Fig. 3).

Alghoul and Codner [30,32] suggested that the ligaments or the fascia in relation to the parotid gland have structural variation in accordance to the parotid fascia over the parotid gland and vary in size, density, and configuration depending on the size and extent of the parotid gland.

Less well-known anatomic variation of the platysma muscle may add another element of confusion. The classification of the platysma muscle presented by Bae et al. [33] reveals a better understanding of the variability in the location and direction of the posterior fiber of the platysma, where the ligamentous attachment should be located.

\section{Platysma Auricular Fascia (PAF, Mendelson [19,20])}

Alghoul and Codner [30] mistakenly noted in their article that Mendelson coined the term 'platysma auricular fascia' (PAF). In reality, Furnas [17] named the platysma auricular fascia $[4,17,18]$, and even in the article, Mendelson reported that the PAF combines the part of the SMAS layer between the ear cartilage and the posterior edge of the platysma [19,20,34] (Fig. 4). In other words, Mendelson believes that the platysma auricular ligament by Furnas (1989) is synonymous to the parotid cutaneous ligament by Stuzin (1992), and that indicates of it to be a lower portion of the PAF [20].

Conceptual arguments about the independence of the platysma auricular fascia are related to where it originates. In contradiction to Mendelson's suggestion of an auricular cartilaginous origin, our cadaveric findings revealed a superficial nature with fibrous connection with the dermis of the inferior earlobe and obvious structural differentiation from the deep fascia, which support the notion that the PAF is a component of the SMAS layer.

\section{Fig. 3. The ligamentous structure of the preauricular area}

(A) Schematic illustration of the parotid cutaneous ligament, platysma auricular fascia, and preauricular parotid cutaneous ligament. 'Parotid cutaneous ligament' (Stuzin 1992), 'platysma auricular fascia' (Furnas 1994) and 'preauricular parotid cutaneous ligament' (Özdemir 2002) are terms that have been used to denote a broad range of fibrous connective tissue in the preauricular area. (B) Fresh frozen cadaver dissection reveals that upon cutting open the platysma auricular ligament, the parotid cutaneous ligaments are exposed at the preauricular area. Diamonds, parotid cutaneous ligaments; Heart, skin flap; Clover, superficial musculoaponeurotic system.

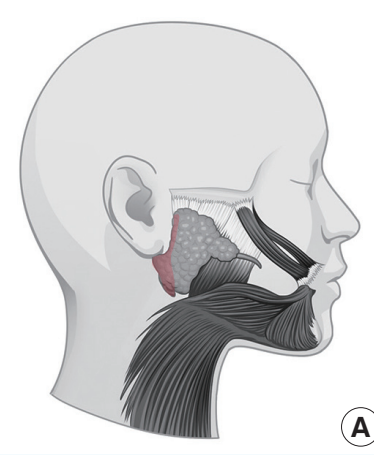

(A)

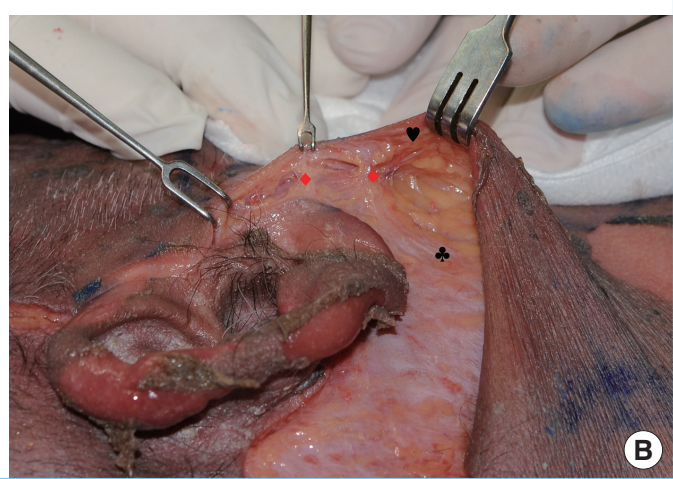


Temporoparotid fascia (Lore 1973 [24,25]), Lore's fascia (Labbé 2006 [21-23]) and tympanoparotid fascia (Labbé 2006 [21,26])

Gray's anatomy describes the parotid fascia as thick and broad anteriorly and thin and translucent membranous posteriorly [35]. Lore [24] named the fascial structure in front of the tragus the 'temporoparotid fascia', and Labbé [21] gave this structure a different name, the 'tympanoparotid fascia' (Lore's fascia). In 2006, Labbé et al. reported that the tympanoparotid fascia originates from the tympanomastoid fissure [26].

The definition of the tympanoparotid fascia is also controversial. Mendelson [19] denied the isolated concept of Lore's fascia and regarded it as a portion of the PAF immediately in front of the lower tragus [20]. O'Brien et al. [31] asserted that, actually, Lore's fascia was a completely different structure from the platysma auricular ligament.

\section{Fig. 4. Platysma auricular fascia (PAF, Mendelson [2008])}

Schematic illustration of the boundary of the platysma auricular fascia (PAF, Mendelson). In the lateral face, immediately in front of the ear, extending 25-30 $\mathrm{mm}$ forward of the ear cartilage to the posterior border of the platysma is a diffuse area of ligamentous attachment

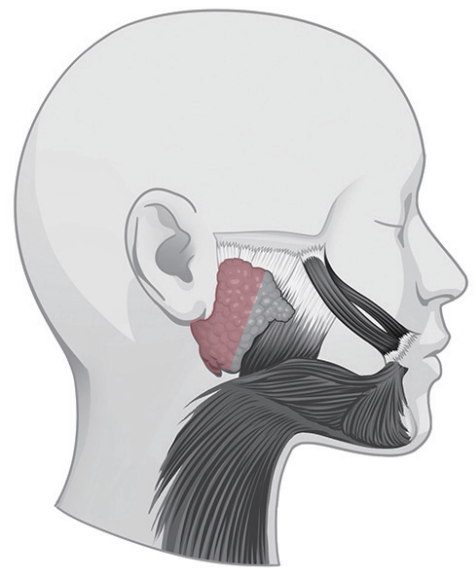

We believe that the tympanoparotid fascia is a dense fibrous tissue that covers the parotid gland, located deeper than the PAF and the SMAS. As it originates from the tympanomastoid fissure, it becomes dense and coarse as it approaches the inferior tragus. The extent of the tympanomastoid fascia arises from the tympanomastoid fissure and covers the ear cartilage superiorly and the parotid fascia anteriorly. As you see in the figure, it is obviously a distinct structure compared to the platysma auricular ligament (Fig. 5).

\section{Ligamentous structures found between the anterior border of the parotid gland and the anterior border of the masseter muscle}

Furnas [3] observed that aponeurotic connections were sometimes seen between the anterior platysma and the skin of the middle and anterior cheek (Fig. 6). Attaching a fibrous connec-

\section{Fig. 5. Cadaveric dissection of the preauricular area}

The tympanoparotid fascia is a separate layer from the platysma auricular ligament. red arrow, tympanoparotid fascia; blue arrow, parotid masseteric fascia (deep fascia); white arrow, platysma auricular ligament; heart, skin flap; clover, superficial musculoaponeurotic system.

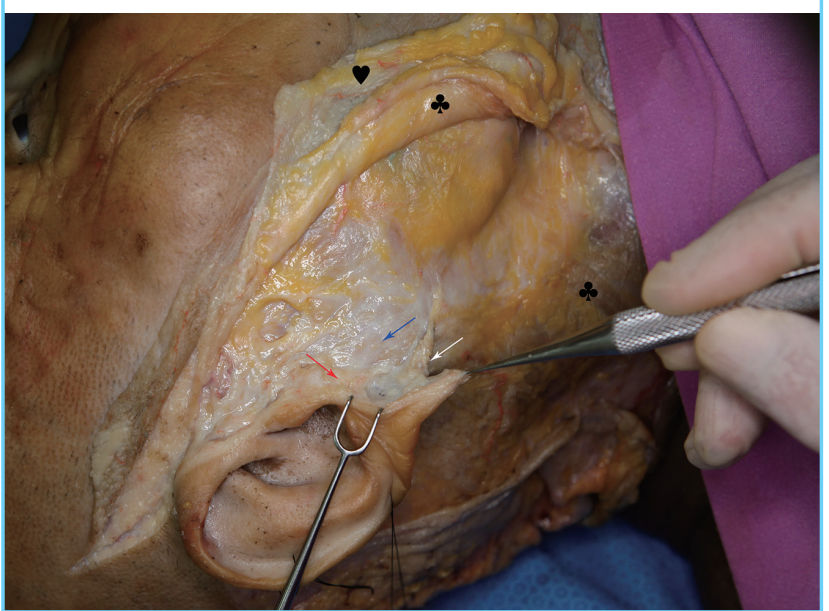

Fig. 6. The anterior platysma-cutaneous ligament (Furnas 1989)

(A) Schematic illustration of the anterior platysma-cutaneous ligament. The aponeurotic connections can be seen between the anterior platysma and the skin of the middle and anterior cheek. (B) Fresh frozen cadaveric dissection over the preparotid region shows that aponeurotic connections exist between the SMAS and the skin. Diamond, anterior platysma-cutaneous ligament; Heart, skin flap; Clover, superficial musculoaponeurotic system (SMAS); Spade, zygomatic arch.

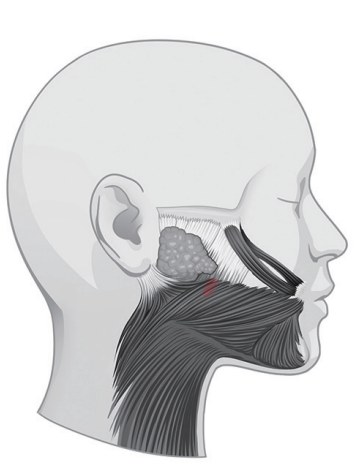

(A) 
tion to the platysma means that it has a septal form rather than a significant ligamentous form. Observing what was previously called the anterior platysma cutaneous ligament by Furnas [3], originating along the anterior border of the masseter, Stuzin [5] proposed the term 'masseteric cutaneous ligament' [8]. Reports differ with regard to the origin of the masseteric cutaneous ligament: whether it arises along the anterior border of the masseter muscle $[5,8,36]$ (Fig. 7 ), $1-2 \mathrm{~cm}$ posterior to the anterior border [6], or even from the middle portion of the muscle (Özdemir) (Fig. 8) [12]. The excursion of the origin definitely has to be closely related to the structural variation in accordance to the intersecting area of the masseteric fascia and the parotid fascia in relation to the size of the parotid gland $[25,30,32,37]$. Thus, each authors have suggested different nomenclature for the masseteric cutaneous ligament or describe it with different anatomic locations (Figs. 6-8) [3,5,12].

The masseteric cutaneous ligaments were previously thought to arise from the masseteric fascia, but it was recently revealed that the upper masseteric ligament originates from the maxillary buttress [15].

\section{Platysma cutaneous ligament (Özdemir [12])}

Özdemir et al. [12] observed a septal form of adhesion at the anterior platysma, and at the mandibular body and angle, and they called it the platysma cutaneous ligament (Fig. 9). The platysma cutaneous ligament by Özdemir et al. (2002) indicates the mandibular septum along the mandibular border, which is a completely different structure from the anterior platysma cuta-

\section{Fig. 9. The platysma cutaneous ligament (Özdemir 2002)}

A schematic illustration of the platysma cutaneous ligament (Özdemir 2002) describes its location long the mandibular border.

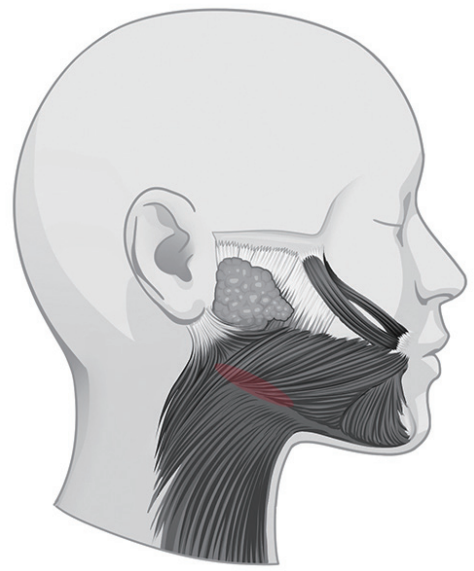

\section{Fig. 7. The masseteric cutaneous ligament (Stuzin 1992)}

(A) Schematic illustration of the masseteric cutaneous ligament. This ligament exists along the anterior border of the masseter muscle. (B) Fresh frozen cadaveric dissection shows the fibrous condensation along the anterior border of the masseter muscle, connecting the skin flap and the SMAS flap. Diamonds, masseteric cutaneous ligaments; Heart, skin flap; Clover, superficial musculoaponeurotic system (SMAS).

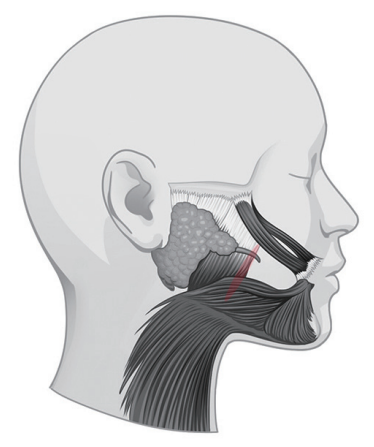

(A)

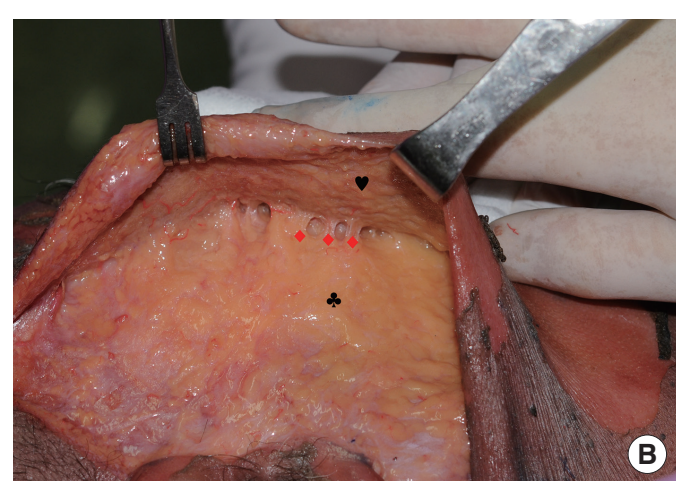

Fig. 8. The parotid masseteric cutaneous ligament (Özdemir 2002)

(A) Schematic illustration of the parotid masseteric cutaneous ligament. This ligament exists at a location where the anterior parotid makes the transition onto the fascia of the masseter muscle. (B) The parotid masseteric ligament is $1-2 \mathrm{~cm}$ posterior to the anterior border or can even originate from the middle portion of the muscle. Diamond, parotid masseteric ligament; Black asterisk, parotid gland; Blue asterisk, masseter muscle.

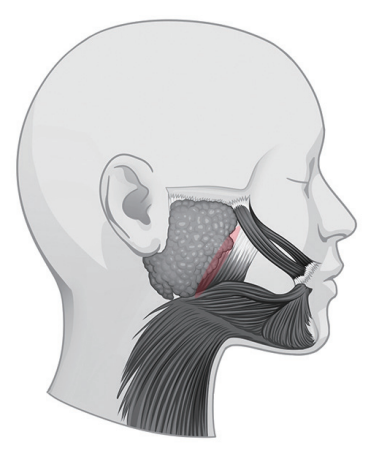

(A)

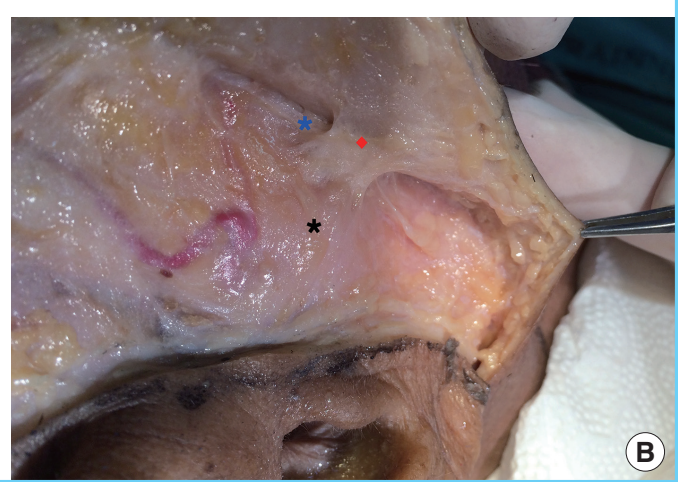


neous ligament by Furnas. Reece et al. [27] also made use of the term "platysma cutaneous ligament" and classified the mandibular septum as an irrelevant structure in relation to the fat compartments, but the location and description match, indicating the same structure.

\section{The extent of the zygomatic ligament}

The zygomatic ligament travels from the zygomatic bone to the dermis, and it would assist in a better surgical understanding in two different, subcutaneous layers and subSMAS level dissection. The actual subcutaneous findings of the zygomatic cutaneous ligament can be described as firm fibrous structures existing along the border of the zygomatic arch, initiating from just in front of the tragus (Fig. 10).

Several studies have made their investigation under different reference points. The subSMAS level dissection setting, collecting measurements of taut and dense attachments of the zygomatic ligaments, may offer quite a difference range of measurements taken from the bone or the subcutaneous level [3,12-14].

There is variability in the difference in measurements. For example, Furnas [3] provided measurements for a typical bundle of the zygomatic ligament $3 \mathrm{~mm}$ in width and $0.5 \mathrm{~mm}$ in thickness located $4.5 \mathrm{~cm}$ anterior to the tragus. On the other hand, Özdemir et al. [12] measured the zygomatic ligament dimensions at $1.8-3.4 \times 0.29-0.34 \mathrm{~cm}$ in men and $1.6-3.0 \times 0.27-0.33$ $\mathrm{cm}$ in women and reported that it was located $3.9-4.8 \mathrm{~cm}$ anterior to the tragus.

The latter group with larger surface measurements of the zygo-

\section{Fig. 10. Zygomatic cutaneous ligaments on the zygomatic arch}

Zygomatic cutaneous ligaments are found along the zygomatic arch, initiating in front of the tragus and found above and/or below the zygomatic arch. Diamonds, zygomatic cutaneous ligaments; blue diamond, anterior platysma cutaneous ligament (Furnas 1989); asterisk, zygomatic arch; heart, skin flap; clover, superficial musculoaponeurotic system.

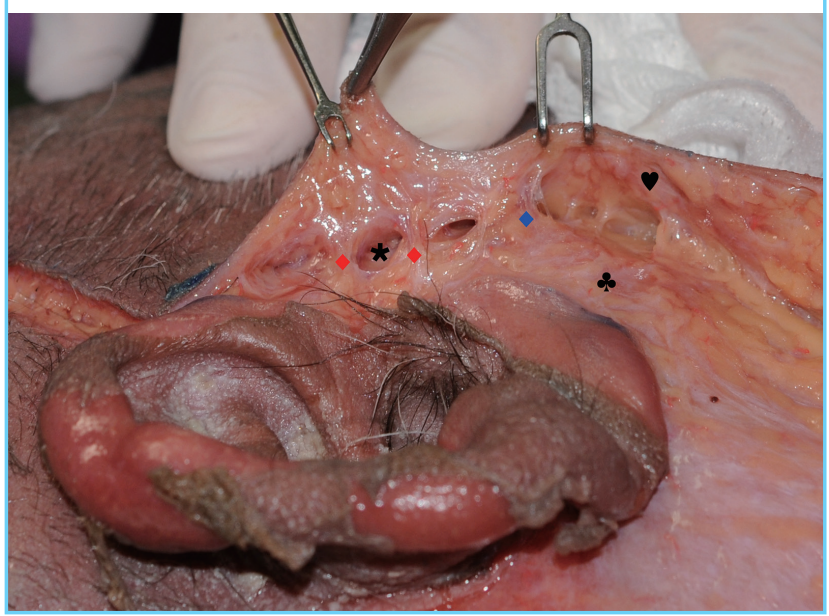

matic ligament must have adopted more cutaneous and histologic evaluation compared to the previous study by Furnas. Presenting the range in measurements shows that the structure may vary according to individual variation of the cadaver subjects, but it is also important to consider how to acquire more consistent reference points for more comparable measurements.

However, most papers offering definitions of the zygomatic ligament still choose to state that it is approximately $4 \mathrm{~cm}$ from the tragus $[3,12,14]$, limited only to a bony attachment area to the subcutaneous portion of the zygomatic ligament. Investigation of the subcutaneous ligamentous attachment of the zygomatic ligament would also be worthwhile.

Subcutaneous findings of the zygomatic cutaneous ligament can be described as firm fibrous structures existing along the lower and/or upper border of the zygomatic arch, initiating from just in front of the tragus where the zygomatic arch starts (Fig. 10).

There also exists a distinct variation in the extent of the zygomatic ligament at the subSMAS level. Alghoul et al. [14] divides it into two groups, observing the main zygomatic ligament approximately $4 \mathrm{~cm}$ from the tragus, and the minor zygomatic ligaments arising $2 \mathrm{~cm}$ away. Stuzin [5] noted a particularly stout ligament originating along the most medial portion of the zygoma, medial to the zygomatic minor (Fig. 11).

The zygomatic ligament described by Mendelson takes its course along the origins of the facial expression muscles; the zygomaticus major, the zygomaticus minor, and the levator labii superioris muscle. He also stated that the particularly strong

Fig. 11. The area of the zygomaticus major and minor is dissected in a fresh frozen cadaver

Easily observed in the fresh frozen cadaver dissection, zygomatic ligaments are found extending further medially along the zygomaticus minor muscle. Diamonds, zygomatic ligaments; black asterisk, zygomaticus major; red asterisk, zygomaticus minor; black asterisk, zygomaticus major; blue asterisk, orbicularis oculi muscle; clovers, reflected superficial musculoaponeurotic system flap.

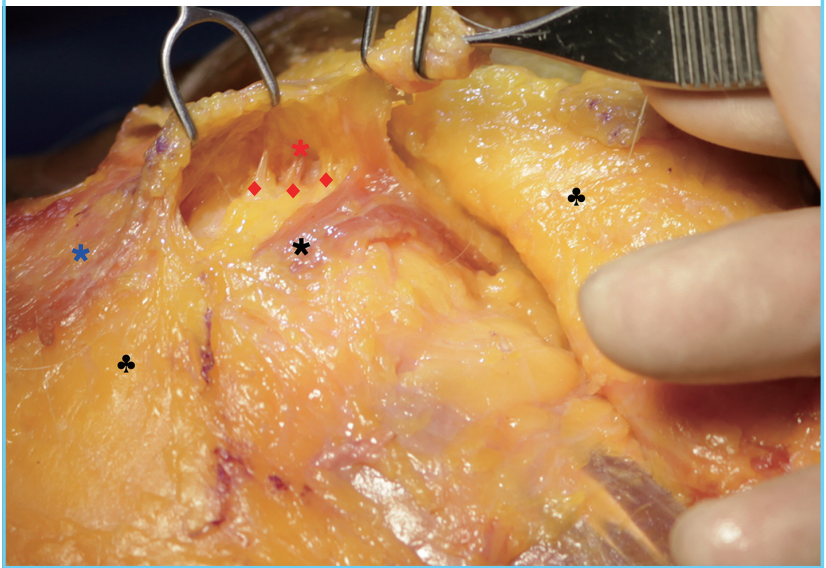


main zygomatic ligament originates from the lateral portion of the zygomaticus major muscle $[9,11,28]$.

\section{DISCUSSION}

\section{Reasons for confusion}

Advances in anatomical evaluation of the retaining ligaments, and information provided by detailed histologic sections, are offering more specific classifications of what was previously considered the same retaining ligament. Varying concepts applied to each retaining ligament for each specified purpose and targeted surgical techniques have influenced the naming of the retaining ligaments in the face.

We believe that since the time the 'fibrous attachment' was described by Furnas, there has been no extraordinary discovery of a new retaining ligament in the cheek. However, the introduction of new nomenclature for the retaining ligaments has resulted from different dissection or surgical techniques which identify different reference points.

\section{Similar location but different nomenclature}

An identical anatomic structure can logically be described utilizing similar but different anatomic structures [3,5,12]. Many have previously adopted the platysma as an emphasized landmark for description, but this was later substituted with the parotid fascia or the muscle fascia for its relevance as a point of origin.

\section{Confusion in classification}

We can easily find different classification systems for facial retaining ligaments. Stuzin (1992), as well as Furnas, largely classified the ligaments into two categories: the osteocutaneous ligament, which keeps its origin at the bone and the other, a supporting ligament that arises from the superficial and deep fascia (Two supporting ligaments mentioned are the parotidocutaneous ligament and masseteric ligament) [3,5,8]. Moss et al. [10] presented a revised classification based on a gross morphology of the 'true ligaments' (Table 2).

\section{Conceptual confusion}

Before the time when Furnas (1989) adopted the term 'ligament' to describe these tissues in the face, Bosse and Papillon [38] stated, "at the malar eminence we have found [the SMAS] to be quite solidly bound to the malar bone by vertical fibrous septa", and Owsley [36] also used the term 'vertical septum.

Varying descriptions of commonly understood fibrous attachments—patch [1], ligament [3,5,12], fascia [17,19], septum $[10,28,36,38]$ etc. - can be another reason for confusion.

The generally accepted concept limits the use of the term 'ligament' to structures with a full interconnection between the bone and the skin, whereas 'fascia' is used when it is related to the parotid fascia or the masseteric fascia.

Moreover, the relatively loose and linear pattern of the septal formation is widely accepted as a 'septum'. Although the word, 'septal boundary', confined to refer to the facial fat compartment by Reece et al. [27], Rohrich, and Pessa [39], is a different use of the same term.

We believe that the facial ligaments are limited to playing a role as a uniform dense fibrotic tissue in offering safe passage for the vessel and nerve to traverse. The zygomatic, upper and midmasseteric and mandibular ligaments are good examples. Besides these, any ligamentous structure in the face that does not convey vessels or nerves is more suitably described as a fibrous attachment'. Such structures include the platysma auricular ligament and Lore's fascia. Any septum in the face should be defined as a boundary between one area and another, which interconnects the overlying facial muscles to the underlying tissue.

McGregor was the first and the only one to mention the term 'patch', and it has never been used since.

\section{Confusion according to the intention of naming}

Included in this type of confusion is reading too much or differently into what was phrased by the author who named a structure, giving diametrically different descriptions, or giving what is thought to be a different but more accurate version of the nomenclature.

\section{Table 2. Different classifications of the retaining ligament of the cheek}

\begin{tabular}{|lllll|}
\hline \multicolumn{2}{c}{ Furnas (bone \& platysma) } & \multicolumn{1}{c}{ Stuzin 1992 (bone \& fascia) } & Mendelson (Morphologic characteristics) \\
\hline Bone origin & Zygomatic lig & True osterocutaneous & Zygomatic & True ligaments \\
& Mandibular lig & & Mandibular & Zygomatic \\
\multirow{3}{*}{ Platysma origin } & Platysma auricular & Superificial \& deep fascia origin & Parotid cutaneous & \\
& Anterior platysma-cutaneous & (supporting ligament) & Masseteric cutaneous & \\
\hline
\end{tabular}

The retaining ligaments of the cheek have been described with varying nomenclature systems due to different classification schemes by each namer. Furnas and Stuzin use a similar bone origin, but differ in their opinion about the soft tissue origin. Mendelson developed his own classification according to the morphology of the fibrous attachments. Although various papers have applied individual rationales in naming the facial retaining ligaments, the consistency among authors in using the terms 'zygomatic,' 'mandibular,' and 'masseteric' has confused the issue. 
When Furnas and many other authors stated their opinion that McGregor's patch is synonymous to the zygomatic ligament, or when some equated the platysma auricular ligament (Furnas 1989) and the parotid cutaneous ligament (Stuzin 1992) with the platysma auricular fascia (Mendelson 2008), these distinctions are owing to a discrepancy in interpretation.

\section{Variations in the subject}

Advances in anatomy should take statistical variation of the cadaver subject into account. It is widely accepted that the parotid fascia is of critical relevance as a rule of origin in relation to the size and location of the parotid gland or the direction of the platysma muscle fibers. For these reasons, the origins of the retaining ligaments between the fascia of the platysma can be confusing.

\section{Variation caused by the surgical technique $[8,20,40-42]$}

For specific techniques requiring little skin undermining with a similar vector pulling the deep and superficial tissue lifting, mentioning the subcutaneous ligamentous attachments is unimportant. But when undermining of the skin flap is separate from deep tissue dissection, or when the vectors differ for pulling superficial and deep tissues, the surgical technique needed for a good outcome is intimately related to a thorough understanding of the subcutaneous ligamentous attachments.

The spatial concept of Mendelson's 'composite facelift' technique coincided with his anatomic categorization of the facial retaining ligaments as adhesion, septum, and space [41]. Minimal skin dissection performed in his technique also left out the subcutaneous concept in his studies, producing a conflicting concept when applied to the previously described conventional retaining ligament.

\section{CONCLUSIONS}

The recent popularity of thread and filler injection procedures has expanded the need for surgeons to develop a thorough understanding of the cutaneous retaining ligaments. Various kinds of thread procedures have been adopted, each with a more complex mechanism as the thread itself evolves. To improve tissue manipulation, surgeons must understand what each thread is supposed to accomplish technically and apply the thread appropriately to fit the patient's unique facial anatomy. This includes an understanding of tissue mobility and fibrous areas for thread anchoring. Filler injection within, above, or below the retaining ligaments will alter the aesthetics or outcomes.

The nomenclature and more detailed descriptions of these structures have been presented inconsistently in the literature. We propose three guidelines for evaluating nomenclature when such discrepancies exist among experts: (1) Understand the intention of the author in naming the tissue. (2) Provide justification when suggesting a new term. (3) Perform further anatomical investigation relative to unchanging reference points.

\section{REFERENCES}

1. McGregor M. Face lift techniques. Proceedings of the 1st Annual Meeting of the California Society of Plastic Surgeons; 1959; Yosemite, CA.

2. Kaye BL. The extended face-lift with ancillary procedures. Ann Plast Surg 1981;6:335-46.

3. Furnas DW. The retaining ligaments of the cheek. Plast Reconstr Surg 1989;83:11-6.

4. Ozdemir R, Kilinc H, Unlu RE, et al. Anatomicohistologic study of the retaining ligaments of the face and use in face lift: retaining ligament correction and SMAS plication. Plast Reconstr Surg 2002;110:1134-49.

5. Stuzin JM, Baker TJ, Gordon HL. The relationship of the superficial and deep facial fascias: relevance to rhytidectomy and aging. Plast Reconstr Surg 1992;89:441-9.

6. Mendelson BC. Extended sub-SMAS dissection and cheek elevation. Clin Plast Surg 1995;22:325-39.

7. Owsley JQ. Elevation of the malar fat pad superficial to the orbicularis oculi muscle for correction of prominent nasolabial folds. Clin Plast Surg 1995;22:279-93.

8. Stuzin JM, Baker TJ, Gordon HL, et al. Extended SMAS dissection as an approach to midface rejuvenation. Clin Plast Surg 1995;22:295-311.

9. Mendelson BC. SMAS fixation to the facial skeleton: rationale and results. Plast Reconstr Surg 1997;100:1834-42.

10. Moss CJ, Mendelson BC, Taylor GI. Surgical anatomy of the ligamentous attachments in the temple and periorbital regions. Plast Reconstr Surg 2000;105:1475-90.

11. Mendelson BC, Muzaffar AR, Adams WP Jr. Surgical anatomy of the midcheek and malar mounds. Plast Reconstr Surg 2002;110:885-96.

12. Ozdemir R, Kilinc H, Unlu RE, et al. Anatomicohistologic study of the retaining ligaments of the face and use in face lift: retaining ligament correction and SMAS plication. Plast Reconstr Surg 2002;110:1134-47.

13. Hwang K, Kim DH, Kim DJ, et al. Anatomy and tensile strength of the zygomatic ligament. J Craniofac Surg 2011; 22:1831-3.

14. Alghoul M, Bitik O, McBride J, et al. Relationship of the zygomatic facial nerve to the retaining ligaments of the face: the Sub-SMAS danger zone. Plast Reconstr Surg 2013;131: 245e-252e. 
15. Doumit G, Gharb BB, Rampazzo A, et al. Surgical anatomy relevant to the transpalpebral subperiosteal elevation of the midface. Aesthet Surg J 2015;35:353-8.

16. Botti G. Midface and neck aesthetic plastic surgery. Vol 1. Parma: Acta Medica Edizioni; 2012.

17. Furnas DW. The superficial musculoaponeurotic plane and the retaining ligaments of the face. In: Psillakis JM, editor. Deep face-lifting techniques. New York: Thieme Medical 1994. p.221.

18. Furnas DW. Strategies for nasolabial levitation. Clin Plast Surg 1995;22:265-78.

19. Mendelson BC, Freeman ME, Wu W, et al. Surgical anatomy of the lower face: the premasseter space, the jowl, and the labiomandibular fold. Aesthetic Plast Surg 2008;32:18595.

20. Neligan P. Plastic surgery. Vol. 2. 3rd ed. NewYork: Saunders Elsevier; 2013.

21. Labbe D, Franco RG, Nicolas J. Platysma suspension and platysmaplasty during neck lift: anatomical study and analysis of 30 cases. Plast Reconstr Surg 2006;117:2001-7.

22. Fogli AL. Skin and platysma muscle anchoring. Aesthetic Plast Surg 2008;32:531-41.

23. Hodgkinson DJ. Five-year experience with modified Fogli (Lore's fascia fixation) platysmaplasty. Aesthetic Plast Surg 2012;36:28-40.

24. Lore JM. An Atlas of head and neck surgery. Philadelphia: Saunders; 1973.

25. Upile T, Jerjes WK, Nouraei SA, et al. Further anatomical approaches to parotid surgery. Eur Arch Otorhinolaryngol 2010;267:793-800.

26. Hwang K, Nam YS, Kim DJ, et al. Anatomy of tympanoparotid fascia relating to neck lift. J Craniofac Surg 2008;19: 648-51.

27. Reece EM, Pessa JE, Rohrich RJ. The mandibular septum: anatomical observations of the jowls in aging-implications for facial rejuvenation. Plast Reconstr Surg 2008;121:141420.

28. Mendelson BC. Surgery of the superficial musculoaponeurotic system: principles of release, vectors, and fixation. Plast Reconstr Surg 2002;109:824-5.

29. Rossell-Perry P. The zygomatic ligament of the face: a criti- cal review. OA Anat 2013; 1:3.

30. Alghoul M, Codner MA. Retaining ligaments of the face: review of anatomy and clinical applications. Aesthet Surg J 2013;33:769-82.

31. O'Brien JX, Rozen WM, Whitaker IS, et al. Lore's fascia and the platysma-auricular ligament are distinct structures. J Plast Reconstr Aesthet Surg 2012;65:e241-5.

32. Alghoul M, Codner MA. Retaining ligaments of the face. Proceedings of the Southeastern Society of Plastic and Reconstructive Surgery Annual Meeting; 2012 June 2-6; Amelia Island, FL.

33. Bae JH, Youn $\mathrm{KH}, \mathrm{Hu} \mathrm{KS}$, et al. Clinical implications of the extension of platysmal fibers on the middle and lower face. Plast Reconstr Surg 2016;138:365-71.

34. Mendelon B. Facelift anatomy, SMAS retaining ligaments and facial spaces. In: Aston SJ, Steinbrech DS, Walden JL, editors. Aesthetic Plastic Surgery. London: Saunders Elsevier; 2009.

35. Standring S. Gray's anatomy. 39th ed. Edinburgh: Elsevier; 2005.

36. Owsley J. Superficial musculoaponeurotic system platysma face lift. In: Dudley H CD, Russell R, editors. Operative Surgery. London: Butterworth; 1986.

37. Upile T, Jerjes WK, Nouraei SA, et al. Further anatomical approaches to parotid surgery. Eur Arch Otorhinolaryngol 2010;267:793-800.

38. Bosse JP, Papillon J. Surgical anatomy of the SMAS at the malar region. In: Transactions of the 9th International Congress of Plastic and Reconstructive Surgery. New York: McGraw-Hill; 1987. p.348-9.

39. Rohrich RJ, Pessa JE. The retaining system of the face: histologic evaluation of the septal boundaries of the subcutaneous fat compartments. Plast Reconstr Surg 2008;121:1804 9.

40. Hamra ST. Composite rhytidectomy. Plast Reconstr Surg 1992;90:1-13.

41. Hamra ST. Building the Composite Face Lift: A Personal Odyssey. Plast Reconstr Surg 2016;138:85-96.

42. Warren RJ, Aston SJ, Mendelson BC. Face lift. Plast Reconstr Surg 2011;128:747e-764e. 